\title{
ANALYSIS OF NONLINEAR FORCED VIBRATIONS OF FRACTIONALLY DAMPED SUSPENSION BRIDGES SUBJECTED TO THE ONE-TO-ONE INTERNAL RESONANCE
}

\author{
Marina V. Shitikova ${ }^{1,2}$, Aleks L. Katembo ${ }^{1}$ \\ ${ }^{1}$ Voronezh State Technical University, Voronezh, RUSSIA \\ ${ }^{2}$ Research Institute of Structural Physics of the Russian Academy of Architecture and Construction Sciences, \\ Moscow, RUSSIA
}

\begin{abstract}
Nonlinear force driven coupled vertical and torsional vibrations of suspension bridges, when the frequency of an external force is approaching one of the natural frequencies of the suspension system, which, in its turn, undergoes the conditions of the one-to-one internal resonance, are investigated. The method of multiple time scales is used as the method of solution. The damping features are described by the fractional derivative, which is interpreted as the fractional power of the differentiation operator. The influence of the fractional parameters (orders of fractional derivatives) on the motion of the suspension bridge is investigated.
\end{abstract}

Keywords: suspension bridge, nonlinear force driven vibrations, fractional damping, generalized method of multiple time scales

\section{АНАЛИЗ ВЫНУЖДЕННЫХ НЕЛИНЕЙНЫХ КОЛЕБАНИЙ ВИСЯЧИХ МОСТОВ ПРИ НАЛИЧИИ ВНУТРЕННЕГО РЕЗОНАНСА ОДИН-К-ОДНОМУ С ПОМОЩЬЮ ПРОИЗВОДНЫХ ДРОБНОГО ПОРЯДКА}

\author{
М.В. Шитикова ${ }^{1,2}$, А.Л. Катембо \\ ${ }^{1}$ Воронежский государственный технический университет, г. Воронеж, РОССИЯ \\ ${ }^{2}$ Научно-исследовательский институт строительной физики \\ Российской академии архитектуры и строительных наук, г. Москва, РОССИЯ
}

\begin{abstract}
Аннотация: Исследуются нелинейные вынужденные изгибно-крутильные колебания висячего моста при наличии внутреннего резонанса один-к-одному в случае, когда частота возмущающей силы близка одной из собственных частот колебаний. В качестве метода решения используется обобщенный метод многих временных масштабов. Силы демпфирования описываются при помощи производной дробного порядка, которая интерпретируется как дробная степень оператора дифференцирования. Проанализировано влияние париметра дробности на колебания висячего моста.
\end{abstract}

Ключевые слова: висячий мост, нелинейные вынужденные колебания, демпфирование с помощью дробной производной, обобщенный метод многих временных масштабов

\section{INTRODUCTION}

The suspension bridges are unique building structures, as they allow one not only to cover large spans, but also are economically viable. Compared to other types of bridges, suspension bridges have a number of technical and aesthetic advantages, that is why they are so widely used 
in the modern world. The history of suspension bridges met with the largest catastrophe in bridge construction - the collapse of the bridge over the Tacoma River (USA) in 1940 (Tacoma Narrows Bridge). In flexible suspension bridges under the action of various dynamic loads, such as moving load or wind, strong bending-torsional vibrations could occur, sometimes resulting in extremely large amplitudes complicating the normal operation of the bridge, and sometimes causing its destruction. Due to the low damping ability of the suspension bridges, the oscillations could be accompanied by the transfer of energy between different modes of vibrations for a long time even after unloading, which was the cause of their occurrence. This is explained by the phenomenon of internal resonance, when one of the frequencies of free bending vibrations is close in value to one of the natural frequencies of torsional vibrations, which in practice can occur quite often due to the density of the spectrum of the natural frequencies of suspension bridges, which largely depend on the geometric parameters of the bridge.

To analyze the phenomena of the internal resonance during dynamic response of suspension bridges, different mathematical models have been utilized. Thus, the continuous model proposed in [1] has been used in [2-6] to solve the system of nonlinear differential equations describing the dynamics of suspension bridges under one-to-one [2-6] and two-to-one [3-5] internal resonances by means of the multiple time scales perturbation technique [7]. The state-of-the-art survey of the internal phenomena in suspension bridges was made by Shitikova and Rossikhin [8] in their plenary lecture at the 5th European Conference of Civil Engineering held in Florence, Italy in 2014. During this report, the authors passed aloud their opinion that the reason of failure of the Tacoma Narrows Bridge was connected with the internal resonance between vertical and torsional vibrations.

This idea was repeated a year later, in 2015 , by Arioli and Gazzola [9], who trying to explain why did torsional oscillations suddenly appears before the Tacoma Narrows collapse found out that vertical oscillations had become large enough and switched to torsional ones. The fourdegree-of-freedom model accounting for both the flexural-torsional motion of the bridge deck and for the transversal motion of a pair of hangers has been considered in [10], and the internal resonance between the modes of deck and hangers vibrations has been studied. Stability of dynamic response of suspension bridges with due account for the phenomenon of the internal resonance has been considered in [11]. The generation of the force induced internal resonance was recorded during repairs connected with the retrofit of suspension bridges in the U.S.A. [12].

Thus, the potential occurrence of internal resonance phenomena has been identified as the potential cause of critical dynamic states in longspan suspension bridges. Therefore, the task of studying the internal resonance in suspension bridges is very relevant and important.

The first field observations of the vibrations of the Golden Gate suspension bridge were made in the period from 1933 to 1942, when seismological instruments were installed on the piers, towers and cables to measure any vibration that might occur [13]. After the failure of the Tacoma Narrows Bridge in 1940, it was decided to install ten instruments for measuring the vertical movement of the bridge, which worked continuously until 1954. Vincent [14-16] analyzed these recordings of observations of the Golden Gate Bridge vibrations, and the field observations of this bridge were further continued to [17-20]. Thus, the experimental data obtained in [20] showed that different vibrational modes feature different amplitude damping coefficients, and the order of smallness of these coefficients tells about low damping capacity of suspension combined systems, resulting in prolonged energy transfer from one partial subsystem to another. However, the analytical model described in [2] with its further extension in $[3,4]$ allows one to analyze only free undamped vibrations of suspension bridges.

Nonlinear free damped vibrations of suspension 
Analysis of Nonlinear Forced Vibrations of Fractionally Damped Suspension Bridges Subject to One-to-One Internal Resonance

bridges in the cases of the one-to-one internal resonance, when the natural frequency of a certain mode of vertical vibrations is close to the natural frequency of a certain mode of torsional vibrations, and the two-to-one internal resonance, when one natural frequency is nearly twice as large as another natural frequency, have been examined in [5] when damping features of the system are prescribed by the first derivative of the displacement with respect to time. It has been shown that for the both types of the internal resonance the damping coefficient does not depend on the natural frequency of vibrations, but this result is in conflict with the experimental data presented in [20] and [21].

To lead the theoretical investigations in line with the experiment, fractional derivatives were introduced in [22] for describing the processes of internal friction occurring in suspension combined systems at nonlinear free vibrations. The nonlinear suspension bridge model put forward allows one to obtain the damping coefficient dependent on the natural frequency of vibrations.

The overview of the existing research of the internal resonance in suspension bridges could be found in [23,24].

In the present paper, the model proposed in [22] for the analysis of free damped vibrations is generalized to the case of nonlinear forced vibrations of suspension bridges, when the frequency of the external force is close to one of the natural frequencies of the vertical vibrations of the suspension combined system, which is subjected to the condition of the one-to-one internal resonance.

\section{PROBLEM FORMULATION}

To analyze the forced damped vibrations of suspension bridges we will use its classical scheme involving a bisymmetrical thin-walled stiffening girder connected with two suspended cables by virtue of vertical suspensions [25]. The cables are thrown over the pilons and are tensioned by anchor mechanisms. The suspensions are considered as inextensible and uniformly distributed along the stiffening girder. The cables are parabolic, and the contour of the girder's cross-section is underformable. It is assumed that the girder's contour translates as a rigid body vertically (in the $y$-axis direction) on the value of $\eta(z, t)$ and rotates with respect to the girder's axis (the $z$-axis) through the angle of $\varphi(z, t)$ (Fig. 1). The origin of the frame of references is in the center of gravity of the cross section.

It is known for suspension bridges [2-4] that some natural modes belonging to different types of vibrations could be coupled with each other, i.e., the excitation of one natural mode gives rise to another one. Two modes interact more often that not, although the possibility for interaction of a greater number of modes is not ruled out.

Below it would be considered the case when only two modes predominate in the vibrational process, namely: the vertical $n$-th mode with linear natural frequency $\omega_{0 n}$, and the torsional $m$-th mode with the natural frequency $\Omega_{0 m}$.

Under such an assumption the functions $\eta(z, t)$ and $\varphi(z, t)$ could be approximately defined as (using the eigenbase of the associated linear undamped unforced problem)

$$
\begin{aligned}
& \eta(z, t) \sim v_{n}(z) x_{1 n}(t), \\
& \varphi(z, t) \sim \Theta_{m}(z) x_{2 m}(t),
\end{aligned}
$$

where $x_{1 n}(t)$ and $x_{2 m}(t)$ are the generalized displacements, and $v_{n}(z)$ and $\Theta_{m}(z)$ are natural shapes of the two interacting modes of vibrations.

When the harmonic force $F=\hat{F} \cos \left(\omega_{F} t\right)$ is applied at the center of the suspension bridge, then the equations of its forced vibrations are written in the dimensionless form as (what is the immediate generalization of the approach proposed in [22] by adding the external vertical excitation with amplitude $\hat{F}=$ const and frequency $\omega_{F}$ ) 

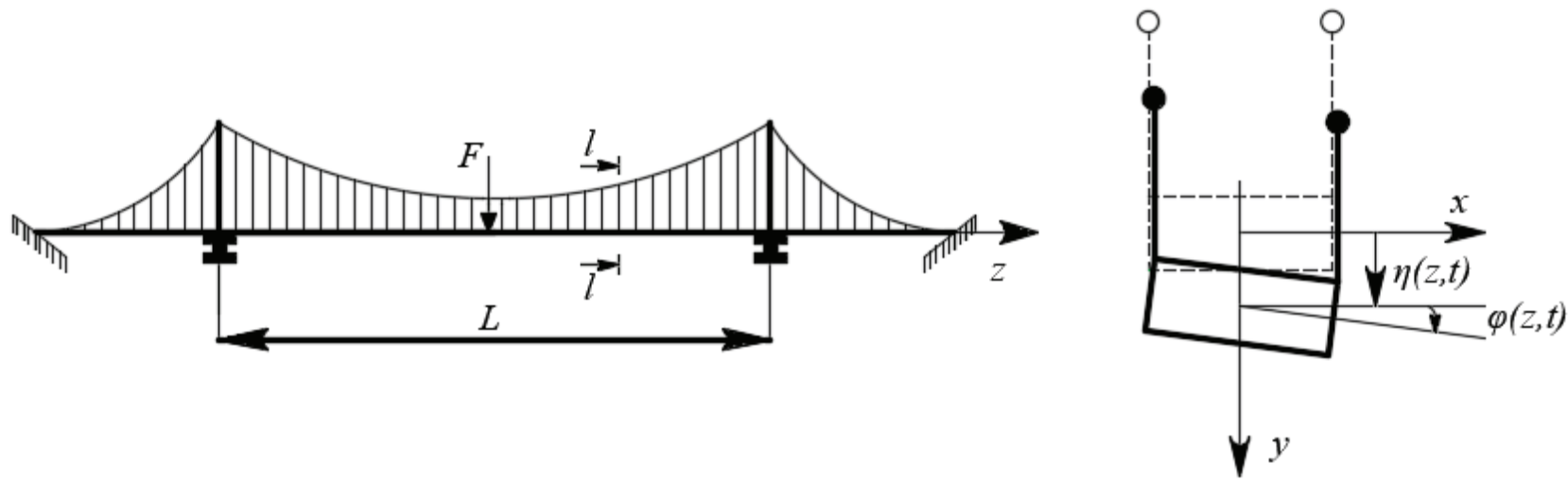

Figure 1. Scheme of a suspension bridge.

$$
\begin{aligned}
& \ddot{x}_{1 n}+\omega_{0 n}^{2} x_{1 n}+\beta D_{0+}^{\gamma} x_{1 n}+a_{11}^{n} x_{1 n}^{2}+a_{22}^{n m} x_{2 m}^{2} \\
& +\left(b_{11}^{n} x_{1 n}^{2}+b_{22}^{n m} x_{2 m}^{2}\right) x_{1 n}=\hat{F} \cos \left(\omega_{F} t\right), \\
& \ddot{x}_{2 m}+\Omega_{0 m}^{2} x_{2 m}+\beta D_{0+}^{\gamma} x_{2 m}+a_{12}^{n m} x_{1 n} x_{2 m} \\
& +\left(c_{11}^{n m} x_{1 n}^{2}+c_{22}^{m} x_{2 m}^{2}\right) x_{2 m}=0,
\end{aligned}
$$

where $a_{i j}, b_{i i}$, and $c_{i i}(i=1,2, j=2)$ are certain dimensionless coefficients which are defined in [2,22] (subsequently the indices $n$ and $m$ are omitted for ease of presentation), dots denote differentiation with respect to time, the terms $\beta D_{0+}^{\gamma_{1}} x_{1}$ and $\beta D_{0+}^{\gamma_{2}} x_{2}$ characterize inelastic reaction of the system, $\beta$ is the viscosity coefficient, the fractional derivative $D_{0+}^{\gamma} x\left(\gamma=\gamma_{1}\right.$ or $\left.\gamma_{2}\right)$ is defined as follows [26]

$$
D_{0+}^{\gamma} x=\frac{d}{d t} \int_{0}^{t} \frac{x\left(t-t^{\prime}\right) d t^{\prime}}{\Gamma(1-\gamma) t^{\prime \gamma}} \quad(0<\gamma \leq 1)
$$

$\gamma$ is the order of the fractional derivative (fractional parameter), and $\Gamma(1-\gamma)$ is the Gamma-function.

Let us consider the case of the one-to-one internal resonance, as well as suppose that the frequency of the external force is close to the natural frequency of the interacting modes, i.e.,

$$
\omega_{0} \approx \Omega_{0} \approx \omega_{F}
$$

Note that the influence of the detuning parameter characterizing the small difference in magnitudes of the natural frequencies $\omega_{0}$ and $\Omega_{0}$ has been investigated in $[4,6,24]$.

Since for finding the solution of equations (2) we will use the method of multiple time scales, where the functions $e^{ \pm i \omega t}$ are utilized as the main harmonic functions, then in order to carry out the calculations the following formulas will be utilized [27]

$$
\begin{gathered}
D_{0+}^{\gamma} e^{ \pm i \omega t}=D_{+}^{\gamma} e^{ \pm i \omega t}+\frac{\sin \pi \gamma}{\pi} \int_{0}^{\infty} \frac{u^{\gamma} e^{-u t} d u}{u \pm i \omega}, \\
D_{+}^{\gamma} e^{ \pm i \omega t}=( \pm i \omega)^{\gamma} e^{ \pm i \omega t}
\end{gathered}
$$

where $D_{+}^{\gamma}$ is obtained from (3) changing the low limit to $-\infty$.

It has been shown in [28] and [29] that the second term in formula (5) does not produce secular terms in the method of multiple time scales under the limitation of the zero- and first-order approximations. In other words, this term could be neglected in further consideration, and it is possible to use the approximate formula

$$
D_{0+}^{\gamma} e^{ \pm i \omega t} \approx D_{+}^{\gamma} e^{ \pm i \omega t}
$$

If we take into account formula (5.82) from [26] 
Analysis of Nonlinear Forced Vibrations of Fractionally Damped Suspension Bridges Subject to One-to-One Internal Resonance

$$
D_{+}^{\gamma} e^{ \pm i \omega t}=\left(\frac{d}{d t}\right)^{\gamma} e^{ \pm i \omega t}
$$

then from the combination of (7) and (8) it follows the relationship

$$
D_{0+}^{\gamma} e^{ \pm i \omega t} \approx\left(\frac{d}{d t}\right)^{\gamma} e^{ \pm i \omega t}
$$

which will be used in further calculations.

\section{METHOD OF SOLUTION}

We will seek the solution for two cases:

(1) $\beta=\varepsilon \mu$ and that $\hat{F}=\varepsilon^{2} f$,

and

(2) $\beta=\varepsilon^{2} \mu$ and that $\hat{F}=\varepsilon^{3} f$,

where a small parameter $\varepsilon$ is introduced as a bookkeeping device to indicate the smallness of terms [7].

In these cases, an approximate solution of equations (2) for small amplitudes weakly varying with time can be represented by an expansion in terms of different time scales

$$
\begin{aligned}
& x_{1}(t)=\varepsilon x_{11}\left(T_{0}, T_{1}, T_{2}\right)+\varepsilon^{2} x_{12}\left(T_{0}, T_{1}, T_{2}\right)+ \\
& +\varepsilon^{3} x_{13}\left(T_{0}, T_{1}, T_{2}\right)+\ldots, \\
& x_{2}(t)=\varepsilon x_{21}\left(T_{0}, T_{1}, T_{2}\right)+\varepsilon^{2} x_{22}\left(T_{0}, T_{1}, T_{2}\right)+ \\
& +\varepsilon^{3} x_{23}\left(T_{0}, T_{1}, T_{2}\right)+\ldots,
\end{aligned}
$$

where

$$
T_{n}=\varepsilon^{n} t(n=0,1,2)
$$

are new independent variables, $\varepsilon$ is a small parameter which is of the same order of magnitude as the amplitudes, and $\mu$ and $f$ are finite values. Here, $T_{0}=t$ is a fast scale, characterizing motions with the natural frequencies $\omega_{0}$ and $\Omega_{0}$, while

$$
T_{1}=\varepsilon t \text { and } T_{2}=\varepsilon^{2} t
$$

are slow scales, characterizing the modulations of the amplitudes and phases.

Considering that [7]

$$
\begin{aligned}
& d / d t=D_{0}+\varepsilon D_{1}+\varepsilon^{2} D_{2}, \\
& d^{2} / d t^{2}=D_{0}^{2}+2 \varepsilon D_{0} D_{1}+\varepsilon^{2}\left(D_{1}^{2}+2 D_{0} D_{2}\right),
\end{aligned}
$$

as well as applying the expansion of the fractional derivative as it was suggested in Rossikhina and Shitikova [22]

$$
\begin{aligned}
& (d / d t)^{\gamma}=\left(D_{0}+\varepsilon D_{1}+\varepsilon^{2} D_{2}+\ldots\right)^{\gamma}= \\
& =D_{+}^{\gamma}+\varepsilon \gamma D_{+}^{\gamma-1} D_{1}+\frac{1}{2} \varepsilon^{2} \gamma(\gamma-1) D_{+}^{\gamma-2} D_{1}^{2} \ldots
\end{aligned}
$$

where $D_{n}=\partial / \partial T_{n}$,

$$
D_{+}^{\gamma-n} x=\frac{d}{d t} \int_{-\infty}^{t} \frac{x\left(t-t^{\prime}\right) d t^{\prime}}{\Gamma(1-\gamma+n) t^{\prime \gamma-n}}(n=0,1,2)
$$

substituting (10) into (2), and equating the coefficients at like powers of $\varepsilon$ to zero, we obtain to order $\varepsilon$ :

$$
\begin{aligned}
& D_{0}^{2} x_{11}+\omega_{0}^{2} x_{11}=0, \\
& D_{0}^{2} x_{21}+\Omega_{0}^{2} x_{21}=0 ;
\end{aligned}
$$

to order $\varepsilon^{2}$ :

$$
\begin{aligned}
& D_{0}^{2} x_{12}+\omega_{0}^{2} x_{12}=-2 D_{0} D_{1} x_{11}-\mu(2-k) D_{+}^{\gamma} x_{11}- \\
& -a_{11} x_{11}^{2}-a_{22} x_{21}^{2}+(2-k) f \cos \left(\omega_{0} T_{0}\right),
\end{aligned}
$$

$D_{0}^{2} x_{22}+\Omega_{0}^{2} x_{22}=-2 D_{0} D_{1} x_{21}-\mu(2-k) D_{+}^{\gamma} x_{21}-$ $-a_{12} x_{11} x_{21}$ 
to order $\varepsilon^{3}$ :

$D_{0}^{2} x_{13}+\omega_{0}^{2} x_{13}=-2 D_{0} D_{1} x_{12}-\left(D_{1}^{2}+2 D_{0} D_{2}\right) x_{11}-$

$-\mu(2-k) D_{+}^{\gamma} x_{12}-\mu(2-k) \gamma D_{+}^{\gamma-1} D_{1} x_{11}-$

$-\mu(k-1) D_{+}^{\gamma} x_{11}-2 a_{11} x_{11} x_{12}-2 a_{22} x_{21} x_{22}-$

$-b_{11} x_{11}^{3}-b_{22} x_{21}^{2} x_{11}+(k-1) f \cos \left(\omega_{0} T_{0}\right)$,

$D_{0}^{2} x_{23}+\Omega_{0}^{2} x_{23}=-2 D_{0} D_{1} x_{22}-\left(D_{1}^{2}+2 D_{0} D_{2}\right) x_{21}-$

$-\mu(2-k) D_{+}^{\gamma} x_{22}-\mu(2-k) \gamma D_{+}^{\gamma-1} D_{1} x_{21}-$

$-\mu(k-1) D_{+}^{\gamma} x_{21}-a_{12}\left(x_{11} x_{22}+x_{12} x_{21}\right)-$

$-c_{11} x_{11}^{2} x_{21}-c_{22} x_{21}^{3}$.

At $k=1$ and $k=2$, we obtain governing equations for the first and second cases, respectively.

Integrating equations (13) yields

$x_{11}=A_{1}\left(T_{1}, T_{2}\right) e^{i \omega_{0} T_{0}}+\bar{A}_{1}\left(T_{1}, T_{2}\right) e^{-i \omega_{0} T}$,

$x_{21}=A_{2}\left(T_{1}, T_{2}\right) e^{i \Omega_{0} T_{0}}+\bar{A}_{2}\left(T_{1}, T_{2}\right) e^{-i \Omega_{0} T_{0}}$,

where $A_{1}$ and $A_{2}$ are unknown complex functions, and $\bar{A}_{1}$ and $\bar{A}_{2}$ are the complex conjugates of $A_{1}$ and $A_{2}$, respectively.

In order to integrate the sets of equations (14) and (15), it is necessary to consider each case separately.

\subsection{The case $k=1$}

Substituting (19) in equations (18) and integrating, we obtain the expressions for $x_{12}$ and $x_{22}$. Then substituting found $x_{12}$ and $x_{22}$ in equations (15) and using the standard procedure for eliminating the secular terms, we have

$$
\begin{aligned}
& D_{2} a_{1}+\left\lfloor\frac{1}{8} \mu^{2}\left(i \omega_{0}\right)^{2 \gamma-3}(1-2 \gamma)+\right. \\
& \left.+\frac{1}{4} i \frac{f^{2}\left(a_{11}^{2}-3 b_{11}\right)}{\mu^{2} \omega_{0}^{2 \gamma+1}} e^{-2 \pi i \gamma}\right\rfloor a_{1}=0,
\end{aligned}
$$

Now let us substitute (16) into the right-hand sides of equations (14) putting there $k=1$, then gather all terms standing at $e^{i \omega_{0} T_{0}}$ and $e^{-i \omega_{0} T_{0}}$ with due account for (4) and vanish them in order to exclude secular terms. As a result we obtain

$$
\begin{aligned}
& D_{1} A_{1}+\frac{1}{2} \mu\left(i \omega_{0}\right)^{\gamma-1} A_{1}-\frac{f}{4 i \omega_{0}}=0 \\
& D_{1} A_{2}+\frac{1}{2} \mu\left(i \omega_{0}\right)^{\gamma-1} A_{2}=0 \\
& D_{0}^{2} x_{12}+\omega_{0}^{2} x_{12}=-\left(a_{11} A_{1}^{2}+a_{22} A_{2}^{2}\right) e^{2 i \omega_{0} T_{0}}- \\
& -a_{11} A_{1} \bar{A}_{1}-a_{22} A_{2} \bar{A}_{2}+c c \\
& D_{0}^{2} x_{22}+\omega_{0}^{2} x_{22}=-a_{12} A_{1} A_{2} e^{2 i \omega_{0} T_{0}}- \\
& -a_{12} A_{1} \bar{A}_{2}+c c
\end{aligned}
$$

where $c c$ is the complex conjugate part to the preceding terms.

Integrating equations (17), we find

$$
\begin{aligned}
& A_{1}\left(T_{1}, T_{2}\right)=a_{1}\left(T_{2}\right) \exp \left\lfloor-\frac{1}{2} \mu\left(i \omega_{0}\right)^{\gamma-1} T_{1}\right\rfloor+ \\
& +\frac{f}{2 \mu\left(i \omega_{0}\right)^{\gamma}}, \\
& A_{2}\left(T_{1}, T_{2}\right)=a_{2}\left(T_{2}\right) \exp \left\lfloor-\frac{1}{2} \mu\left(i \omega_{0}\right)^{\gamma-1} T_{1}\right\rfloor .
\end{aligned}
$$

$$
\begin{aligned}
& D_{2} a_{2}+\left\lfloor\frac{1}{8} \mu^{2}\left(i \omega_{0}\right)^{2 \gamma-3}(1-2 \gamma)+\right. \\
& \left.+\frac{1}{4} i \frac{f^{2}\left(a_{11} a_{12}-2 c_{11}-\frac{1}{3} a_{12}^{2} \omega_{0}^{-2}\right)}{\mu^{2} \omega_{0}^{2 \gamma+1}} e^{-2 \pi i \gamma}\right] a_{2}=0 .
\end{aligned}
$$

Integrating equations (20) yields 
Analysis of Nonlinear Forced Vibrations of Fractionally Damped Suspension Bridges Subject to One-to-One Internal Resonance

$$
\begin{aligned}
& a_{1}=a_{1}^{0} \exp \left\{T_{2} \mid-\frac{1}{8} \mu^{2}(1-2 \gamma)\left(i \omega_{0}\right)^{2 \gamma-2}-\right. \\
& \left.\left.-\frac{1}{4} \frac{f^{2}\left(a_{11}^{2}-3 b_{11}\right)}{\mu^{2} \omega_{0}^{2 \gamma+1}}(i \cos 2 \pi \gamma+\sin 2 \pi \gamma)\right]\right\}, \\
& a_{2}=a_{2}^{0} \exp \left\{T _ { 2 } \left\lfloor-\frac{1}{8} \mu^{2}(1-2 \gamma)\left(i \omega_{0}\right)^{2 \gamma-3}-\right.\right. \\
& -\frac{1}{4} \frac{f^{2}\left(a_{11} a_{12}-2 c_{11}-\frac{1}{3} a_{12}^{2} \omega_{0}^{-2}\right)}{\mu^{2} \omega_{0}^{2 \gamma+1}} \times \\
& \times(i \cos 2 \pi \gamma+\sin 2 \pi \gamma)]\},
\end{aligned}
$$

$$
\begin{aligned}
& \alpha_{2}=\frac{1}{2} \varepsilon \mu \omega_{0}^{\gamma-1} \sin \left(\frac{\pi \gamma}{2}\right) \times \\
& \times\left[1+\frac{1}{2} \varepsilon \mu(2 \gamma-1) \omega_{0}^{\gamma-2} \cos \left(\frac{\pi \gamma}{2}\right)\right]- \\
& -\frac{1}{4} \varepsilon^{2} \frac{f^{2}\left(a_{11} a_{12}-2 c_{11}-a_{12}^{2} \omega_{0}^{-2} / 3\right)}{\mu^{2} \omega_{0}^{2 \gamma+1}} \sin (2 \pi \gamma), \\
& \Omega_{2}=\omega_{0}\left[1+\frac{1}{2} \varepsilon \mu \omega_{0}^{\gamma-2} \cos \left(\frac{\pi \gamma}{2}\right)+\right. \\
& +\frac{1}{8} \varepsilon^{2} \mu^{2}(2 \gamma-1) \omega_{0}^{2(\gamma-2)} \cos (\pi \gamma)- \\
& \left.-\frac{1}{4} \varepsilon^{2} \frac{f^{2}\left(a_{11} a_{12}-2 c_{11}-a_{12}^{2} \omega_{0}^{-2} / 3\right)}{\mu^{2} \omega_{0}^{2(\gamma+1)}} \cos (2 \pi \gamma)\right] .
\end{aligned}
$$

where $a_{1}^{0}$ and $a_{2}^{0}$ are arbitrary constants.

Considering formulas (10), (16), (19), and (21), we finally obtain

$$
\begin{aligned}
& x_{1}=\varepsilon\left\lfloor 2 a_{1}^{0} e^{-\alpha_{1} t} \cos \Omega_{1} t+\right. \\
& \left.+\frac{f}{\mu \omega_{0}^{\gamma}} \cos \left(\omega_{0} t-\frac{\pi}{2} \gamma\right)\right]+O\left(\varepsilon^{2}\right), \\
& x_{2}=\varepsilon 2 a_{2}^{0} e^{-\alpha_{2} t} \cos \Omega_{2} t+O\left(\varepsilon^{2}\right),
\end{aligned}
$$

where

$$
\begin{aligned}
& \alpha_{1}=\frac{1}{2} \varepsilon \mu \omega_{0}^{\gamma-1} \sin \left(\frac{\pi \gamma}{2}\right) \times \\
& \times\left[1+\frac{1}{2} \varepsilon \mu(2 \gamma-1) \omega_{0}^{\gamma-2} \cos \left(\frac{\pi \gamma}{2}\right)\right]- \\
& -\frac{1}{4} \varepsilon^{2} \frac{f^{2}\left(a_{11}^{2}-3 b_{11}\right)}{\mu^{2} \omega_{0}^{2 \gamma+1}} \sin (2 \pi \gamma), \\
& \Omega_{1}=\omega_{0}\left[1+\frac{1}{2} \varepsilon \mu \omega_{0}^{\gamma-2} \cos \left(\frac{\pi \gamma}{2}\right)+\right. \\
& +\frac{1}{8} \varepsilon^{2} \mu^{2}(2 \gamma-1) \omega_{0}^{2(\gamma-2)} \cos (\pi \gamma)- \\
& -\frac{1}{4} \varepsilon^{2} \frac{f^{2}\left(a_{11}^{2}-3 b_{11}\right)}{\left.\mu^{2} \omega_{0}^{2(\gamma+1)} \cos (2 \pi \gamma)\right],}
\end{aligned}
$$

Reference to the found analytical solution (22) shows that it involves two parts: the first corresponds to the damping vibrations with damping coefficients and nonlinear frequencies dependent on the fractional parameters and describes the transient process, while the second one is nondamping in character and describes forced vibrations with the frequency of the exciting force and with the phase difference depending on the fractional parameter.

\subsection{The case $k=2$}

Let us substitute relations (16) in the right-hand parts of equations (14) at $k=2$. Eliminating secular terms and integrating the equations obtained, we have

$$
\begin{gathered}
D_{1} A_{1}=D_{1} A_{2}=0 \\
x_{12}=\frac{a_{11}}{3 \omega_{0}^{2}} A_{1}^{2} e^{2 i \omega_{0} T_{0}}+\frac{a_{22}}{3 \omega_{0}^{2}} A_{2}^{2} e^{2 i \omega_{0} T_{0}}- \\
-\left(a_{11} A_{1} \bar{A}_{1}+a_{22} A_{2} \bar{A}_{2}\right) \omega_{0}^{2}+c c \\
x_{22}=\frac{a_{12}}{3 \omega_{0}^{2}} A_{1} A_{2} e^{2 i \omega_{0} T_{0}}-\frac{a_{12}}{\omega_{0}^{2}} A_{1} \bar{A}_{2}+c c .
\end{gathered}
$$

From (23) it follows that the functions $A_{1}$ and $A_{2}$ are $T_{1}$-independent.

Substituting then (16) and (24) in equations (15) 
and utilizing the standard procedure for eliminating secular terms, we obtain

$$
\begin{aligned}
& -i D_{2} A_{1}-\frac{1}{2} \mu \omega_{0}^{-1}\left(i \omega_{0}\right)^{\gamma} A_{1}-\lambda_{1} A_{1}^{2} \bar{A}_{1}- \\
& -\lambda_{2} A_{1} A_{2} \bar{A}_{2}+\frac{1}{4} \Gamma_{1} \bar{A}_{1} A_{2}^{2}+\frac{1}{4} \frac{f}{\omega_{0}}=0, \\
& -i D_{2} A_{2}-\frac{1}{2} \mu \omega_{0}^{-1}\left(i \omega_{0}\right)^{\gamma} A_{2}-\lambda_{3} A_{1} \bar{A}_{1} A_{2}- \\
& -\lambda_{4} A_{2}^{2} \bar{A}_{2}+\frac{1}{4} \Gamma_{2} A_{1}^{2} \bar{A}_{2}=0,
\end{aligned}
$$

where coefficients $\lambda_{i}$ and $\Gamma_{j}(i=1,2,3,4$ and $j=1,2)$ are presented in $[2,4]$.

Now we multiply (25a) and (25b) by $\bar{A}_{1}$ and $\bar{A}_{2}$ , respectively, and find their complex conjugates. Adding every pair of the mutually adjoint equations and subtracting one from another, and after all manipulations representing the functions $A_{1}$ and $A_{2}$ in their polar form, i.e.,

$$
\begin{aligned}
& A_{1}\left(T_{2}\right)=a_{1}\left(T_{2}\right) \exp \left[i \varphi_{1}\left(T_{2}\right)\right], \\
& A_{2}\left(T_{2}\right)=a_{2}\left(T_{2}\right) \exp \left[i \varphi_{2}\left(T_{2}\right)\right],
\end{aligned}
$$

as a result we obtain the modulation equations

$$
\begin{aligned}
& \dot{a}_{1}+\frac{1}{2} \mu \omega_{0}^{\gamma-1} \sin \left(\frac{1}{2} \pi \gamma\right) a_{1}-\frac{1}{4} \Gamma_{1} a_{1} a_{2}^{2} \sin \delta+ \\
&+ \frac{1}{4} f \omega_{0}^{-1} \sin \varphi_{1}=0 \\
& \dot{a}_{2}+\frac{1}{2} \mu \Omega_{0}^{\gamma-1} \sin \left(\frac{1}{2} \pi \gamma\right) a_{2}+ \\
& \quad+\frac{1}{4} \Gamma_{2} a_{1}^{2} a_{2} \sin \delta=0 \\
& \dot{\varphi}_{1}-\frac{1}{2} \mu \omega_{0}^{\gamma-1} \cos \left(\frac{1}{2} \pi \gamma\right)-\lambda_{1} a_{1}^{2}-\lambda_{2} a_{2}^{2}+ \\
&+\frac{1}{4} \Gamma_{1} a_{2}^{2} \cos \delta+\frac{1}{4} f \omega_{0}^{-1} a_{1}^{-1} \cos \varphi_{1}=0
\end{aligned}
$$

$$
\begin{aligned}
& \dot{\varphi}_{2}-\frac{1}{2} \mu \Omega_{0}^{\gamma-1} \cos \left(\frac{1}{2} \pi \gamma\right)-\lambda_{3} a_{1}^{2}-\lambda_{4} a_{2}^{2}+ \\
& +\frac{1}{4} \Gamma_{2} a_{1}^{2} \cos \delta=0,
\end{aligned}
$$

where

$$
\delta=2\left(\varphi_{2}-\varphi_{1}\right)
$$

is the phase difference, and a dot denotes differentiation with respect to $T_{2}$.

The set of differential equations (26) subjected to the initial conditions competely describes the modulations of amplitude and phases of forced damped vibrations. An approximate analytical solution of equations (26) could be found by the method of successive approximations.

As the initial approximation, let us consider the solution of the homogeneous part of equations (26):

$$
\begin{aligned}
& \dot{a}_{1}+\frac{1}{2} \mu \omega_{0}^{\gamma_{1}-1} \sin \left(\frac{1}{2} \pi \gamma_{1}\right) a_{1}=0, \\
& \dot{a}_{2}+\frac{1}{2} \mu \Omega_{0}^{\gamma_{2}-1} \sin \left(\frac{1}{2} \pi \gamma_{2}\right) a_{2}=0, \\
& \dot{\varphi}_{1}-\frac{1}{2} \mu \omega_{0}^{\gamma_{1}-1} \cos \left(\frac{1}{2} \pi \gamma_{1}\right)-\sigma_{1}=0, \\
& \dot{\varphi}_{2}-\frac{1}{2} \mu \Omega_{0}^{\gamma_{2}-1} \cos \left(\frac{1}{2} \pi \gamma_{2}\right)-\left(\sigma_{1}-\sigma\right)=0,
\end{aligned}
$$

which has the form

$$
\begin{aligned}
& a_{1}=a_{10} e^{-S_{1} T_{2}}, \quad a_{2}=a_{20} e^{-S_{2} T_{2}}, \\
& \varphi_{1}=S_{3} T_{2}+\varphi_{10}, \quad \varphi_{2}=S_{4} T_{2}+\varphi_{20},
\end{aligned}
$$

where $a_{i 0}$ and $\varphi_{i 0} \quad(i=1,2)$ are, respectively, the initial values of amplitudes and phases to be found from the initial conditions,

$$
\delta_{0}=2\left(\varphi_{20}-\varphi_{10}\right)
$$

is the initial phase difference, and 
Analysis of Nonlinear Forced Vibrations of Fractionally Damped Suspension Bridges Subject to One-to-One Internal Resonance

$$
\begin{aligned}
& S_{1}=\frac{1}{2} \mu \omega_{0}^{\gamma-1} \sin \left(\frac{1}{2} \pi \gamma\right), \\
& S_{2}=\frac{1}{2} \mu \Omega_{0}^{\gamma-1} \sin \left(\frac{1}{2} \pi \gamma\right), \\
& S_{3}=\frac{1}{2} \mu \omega_{0}^{\gamma-1} \cos \left(\frac{1}{2} \pi \gamma\right), \\
& S_{4}=\frac{1}{2} \mu \Omega_{0}^{\gamma-1} \cos \left(\frac{1}{2} \pi \gamma\right) .
\end{aligned}
$$

Now substituting (28) in equations (26) yields

$$
\begin{aligned}
& \dot{a}_{1}+S_{1} a_{1}=\frac{1}{4} \Gamma_{1} a_{10} e^{-\left(S_{1}+2 S_{2}\right) T_{2}} a_{20}^{2} \sin \left(\Sigma T_{2}+\delta_{0}\right)- \\
& -\frac{1}{4} F \omega_{0}^{-1} \sin \left(S_{3} T_{2}+\varphi_{10}\right), \\
& \dot{a}_{2}+S_{2} a_{2}=-\frac{1}{4} \Gamma_{2} a_{10}^{2} e^{-\left(2 S_{1}+S_{2}\right) T_{2}} a_{20} \sin \left(\Sigma T_{2}+\delta_{0}\right), \\
& \dot{\varphi}_{1}-S_{3}=\lambda_{1} a_{10}^{2} e^{-2 S_{1} T_{2}}+\lambda_{2} a_{20}^{2} e^{-2 S_{2} T_{2}}- \\
& -\frac{1}{4} \Gamma_{1} a_{20}^{2} e^{-2 S_{2} T_{2}} \cos \left(\Sigma T_{2}+\delta_{0}\right)- \\
& -\frac{1}{4} F \omega_{0}^{-1} a_{10}^{-1} e^{S_{1} T_{2}} \cos \left(S_{3} T_{2}+\varphi_{10}\right), \\
& \dot{\varphi}_{2}-S_{4}=\lambda_{3} a_{10}^{2} e^{-2 S_{1} T_{2}}+\lambda_{4} a_{20}^{2} e^{-2 S_{2} T_{2}}- \\
& -\frac{1}{4} \Gamma_{2} a_{10}^{2} e^{-2 S_{1} T_{2}} \cos \left(\Sigma T_{2}+\delta_{0}\right),
\end{aligned}
$$

where $\Sigma=2\left(S_{4}-S_{3}\right)$.

$$
\begin{aligned}
& \dot{C}_{1}\left(T_{2}\right)=\frac{1}{4} \Gamma_{1} a_{10} a_{20}^{2} e^{-2 S_{2} T_{2}} \sin \left(\Sigma T_{2}+\delta_{0}\right)- \\
& -\frac{1}{4} F \omega_{0}^{-1} e^{S_{1} T_{2}} \sin \left(S_{3} T_{2}+\varphi_{10}\right), \\
& \dot{C}_{2}\left(T_{2}\right)=-\frac{1}{4} \Gamma_{2} a_{10}^{2} a_{20} e^{-2 S_{1} T_{2}} \sin \left(\Sigma T_{2}+\delta_{0}\right) .
\end{aligned}
$$

Integrating equations (32), we have

$$
\begin{aligned}
& C_{1}\left(T_{2}\right)=-\frac{1}{4} \Gamma_{1} a_{10} a_{20}^{2}\left[2 S_{2} \sin \left(\Sigma T_{2}+\delta_{0}\right)+\right. \\
& \left.+\Sigma \cos \left(\Sigma T_{2}+\delta_{0}\right)\right]\left(4 S_{2}^{2}+\Sigma^{2}\right)^{-1} e^{-2 S_{2} T_{2}}- \\
& -\frac{F}{4 \omega_{0}}\left[S_{1} \sin \left(S_{3} T_{2}+\varphi_{10}\right)-\right. \\
& \left.-S_{3} \cos \left(S_{3} T_{2}+\varphi_{10}\right)\right]\left(S_{1}^{2}+S_{3}^{2}\right)^{-1} e^{S_{1} T_{2}}+C_{10}, \\
& C_{2}\left(T_{2}\right)=\frac{1}{4} \Gamma_{2} a_{10}^{2} a_{20}\left[2 S_{1} \sin \left(\Sigma T_{2}+\delta_{0}\right)+\right. \\
& \left.+\Sigma \cos \left(\Sigma T_{2}+\delta_{0}\right)\right]\left(4 S_{1}^{2}+\Sigma^{2}\right)^{-1} e^{-2 S_{1} T_{2}}+C_{20},
\end{aligned}
$$

where $C_{10}$ and $C_{20}$ are constants of integration.

Considering relationships (33), the amplitude functions take the form

$$
\begin{aligned}
& a_{1}=a_{10} e^{-S_{1} T_{2}}-\frac{1}{4} \Gamma_{1} a_{10} a_{20}^{2}\left[2 S_{2} \sin \left(\Sigma T_{2}+\delta_{0}\right)+\right. \\
& \left.+\Sigma \cos \left(\Sigma T_{2}+\delta_{0}\right)\right]\left(4 S_{2}^{2}+\Sigma^{2}\right)^{-1} e^{-\left(S_{1}+2 S_{2}\right) T_{2}}- \\
& -\frac{F}{4 \omega_{0}}\left[S_{1} \sin \left(S_{3} T_{2}+\varphi_{10}\right)-\right. \\
& \left.-S_{3} \cos \left(S_{3} T_{2}+\varphi_{10}\right)\right]\left(S_{1}^{2}+S_{3}^{2}\right)^{-1} e^{S_{1} T_{2}}+C_{10} e^{-S_{1} T_{2}}, \\
& a_{2}=a_{20} e^{-S_{2} T_{2}}+\frac{1}{4} \Gamma_{2} a_{10}^{2} a_{20}\left[2 S_{1} \sin \left(\Sigma T_{2}+\delta_{0}\right)+\right. \\
& \left.+\Sigma \cos \left(\Sigma T_{2}+\delta_{0}\right)\right]\left(4 S_{1}^{2}+\Sigma^{2}\right)^{-1} e^{-\left(2 S_{1}+S_{2}\right) T_{2}}+C_{20} e^{-S_{2} T_{2}} .
\end{aligned}
$$

use the method of variation of arbitrary functions, and assume the proposed solution in the form

$$
\begin{aligned}
& a_{1}\left(T_{2}\right)=C_{1}\left(T_{2}\right) e^{-S_{1} T_{2}}, \\
& a_{2}\left(T_{2}\right)=C_{2}\left(T_{2}\right) e^{-S_{2} T_{2}},
\end{aligned}
$$

where $C_{1}\left(T_{2}\right)$ and $C_{2}\left(T_{2}\right)$ are arbitrary functions to be found.

Substituting the proposed solution (31) in equations (30) yields

Integrating the third and fourth equations in (30), we obtain the $T_{2}$-functions of the phases of vibration 


$$
\begin{aligned}
& \varphi_{1}=S_{3} T_{2}+\varphi_{10}-\frac{\lambda_{1} a_{10}^{2}}{2 S_{1}} e^{-2 S_{1} T_{2}}-\frac{\lambda_{2} a_{20}^{2}}{2 S_{2}} e^{-2 S_{2} T_{2}}+ \\
& +\frac{1}{4} \Gamma_{1} a_{20}^{2} \frac{2 S_{2} \cos \left(\Sigma T_{2}+\delta_{0}\right)+\Sigma \sin \left(\Sigma T_{2}+\delta_{0}\right)}{4 S_{2}^{2}+\Sigma^{2}} e^{-2 S_{2} T_{2}}- \\
& -\frac{1}{4} \frac{F a_{10}^{-1}}{\omega_{0}} \frac{S_{1} \cos \left(S_{3} T_{2}+\varphi_{10}\right)+S_{3} \sin \left(S_{3} T_{2}+\varphi_{10}\right)}{S_{1}^{2}+S_{3}^{2}} e^{S_{1} T_{2}}+ \\
& +C_{30}, \\
& \varphi_{2}=S_{4} T_{2}+\varphi_{20}-\frac{\lambda_{3} a_{10}^{2}}{2 S_{1}} e^{-2 S_{1} T_{2}}-\frac{\lambda_{4} a_{20}^{2}}{2 S_{2}} e^{-2 S_{2} T_{2}}+ \\
& +\frac{1}{4} \Gamma_{2} a_{10}^{2} \frac{2 S_{1} \cos \left(\Sigma T_{2}+\delta_{0}\right)+\Sigma \sin \left(\Sigma T_{2}+\delta_{0}\right)}{4 S_{1}^{2}+\Sigma^{2}} e^{-2 S_{1} T_{2}}+ \\
& +C_{40},
\end{aligned}
$$

where $C_{30}$ and $C_{40}$ are constants of integration to be determined from the initial conditions.

Since the general solution of the system under consideration is the sum of the particular solution of the inhomogeneous set of equations and the general solution of the corresponding homogeneous system, then the arbitrary constants could be chosen in such a way that the initial conditions of all successive approximations would be zero. Thus, for the first approximation the constants to be found take the form

$$
\begin{aligned}
& C_{10}=\frac{1}{4} \Gamma_{1} a_{10} a_{20}^{2} \frac{2 S_{2} \sin \delta_{0}+\sum \cos \delta_{0}}{4 S_{2}^{2}+\Sigma^{2}}+ \\
& +\frac{F}{4 \omega_{0}} \frac{S_{1} \sin \varphi_{10}-S_{3} \cos \varphi_{10}}{S_{1}^{2}+S_{3}^{2}} \\
& C_{20}=-\frac{1}{4} \Gamma_{2} a_{10}^{2} a_{20} \frac{2 S_{1} \sin \delta_{0}+\sum \cos \delta_{0}}{4 S_{1}^{2}+\Sigma^{2}}, \\
& C_{30}=\frac{\lambda_{1} a_{10}^{2}}{2 S_{1}}+\frac{\lambda_{2} a_{20}^{2}}{2 S_{2}}-\frac{1}{4} \Gamma_{1} a_{20}^{2} \frac{2 S_{2} \cos \delta_{0}+\Sigma \sin \delta_{0}}{4 S_{2}^{2}+\Sigma^{2}}+ \\
& +\frac{1}{4} \frac{F a_{10}^{-1}}{\omega_{0}} \frac{S_{1} \cos \varphi_{10}+S_{3} \sin \varphi_{10}}{S_{1}^{2}+S_{3}^{2}}, \\
& C_{40}=\frac{\lambda_{3} a_{10}^{2}}{2 S_{1}}+\frac{\lambda_{4} a_{20}^{2}}{2 S_{2}}-\frac{1}{4} \Gamma_{2} a_{10}^{2} \frac{2 S_{1} \cos \delta_{0}+\Sigma \sin \delta_{0}}{4 S_{1}^{2}+\Sigma^{2}} .
\end{aligned}
$$

Substitution of the found constants of integration (36) in relationships (34) and (35) results in the approximate analytical solution of the formulated problem.

\section{NUMERICAL RESULTS}

For numerical studies of the influence of the parameters of the fractional derivative viscoelastic model on forced vibrations of suspension bridges, the fourth-order RungeKutta method was used in the "GNU Octave» system for numerical mathematics utilizing different values of the fractional parameter.

Envelopes of the amplitudes of nonlinear vibrations of the Golden Gate Bridge in the case of the internal resonance $\omega_{05}^{s}=\Omega_{03}^{s}=2.61 \mathrm{rad} / \mathrm{sec}$ (according to data presented in [2], the natural frequency of the fifth symmetric mode of vertical vibrations is equal to that of the third symmetric mode of the torsional vibrations) are depicted in Figure 2(a) for free vibrations and in Figure 2(b) for forced vibrations at $f=1$ at different magnitudes of the fractional parameter $\gamma=0,0.15$, and 0.5 . Reference to Fig. 2 shows that the increase in the fractional parameter results in a significant decrease in dimensionless amplitudes of nonlinear oscillations. The energy exchange between the interacting modes takes place both in the case of undamped $(\gamma=0)$ and damped $(0<\gamma \leq 1)$ vibrations, and the action of the external force does not affect this phenomenon.

Dimensionless displacements of the Golden Gate Bridge for forced vibrations are shown in Fig. 3 for different levels of the external force magnitudes. From Fig. 3 it is evident that the displacement $x_{1}$ is more susceptible to a higher vertical force than $x_{2}$. This is due to the fact that $x_{1}$ and $x_{2}$ are responsible for vertical and torsional vibrations, respectively, whence it follows that the $x_{2}$-displacement is weakly sensitive to the increase in the force amplitude $f$. Figure 4 allows one to trace the influence of the level of the external force magnitude on the dimensionless amplitudes of vertical $a_{1}$ and torsional $a_{2}$ vibrations. From Figure 4 it could be seen that the magnitudes of the amplitudes of vertical vibrations are very sensitive to the action of the force. 
Analysis of Nonlinear Forced Vibrations of Fractionally Damped Suspension Bridges Subject to One-to-One Internal Resonance

a)
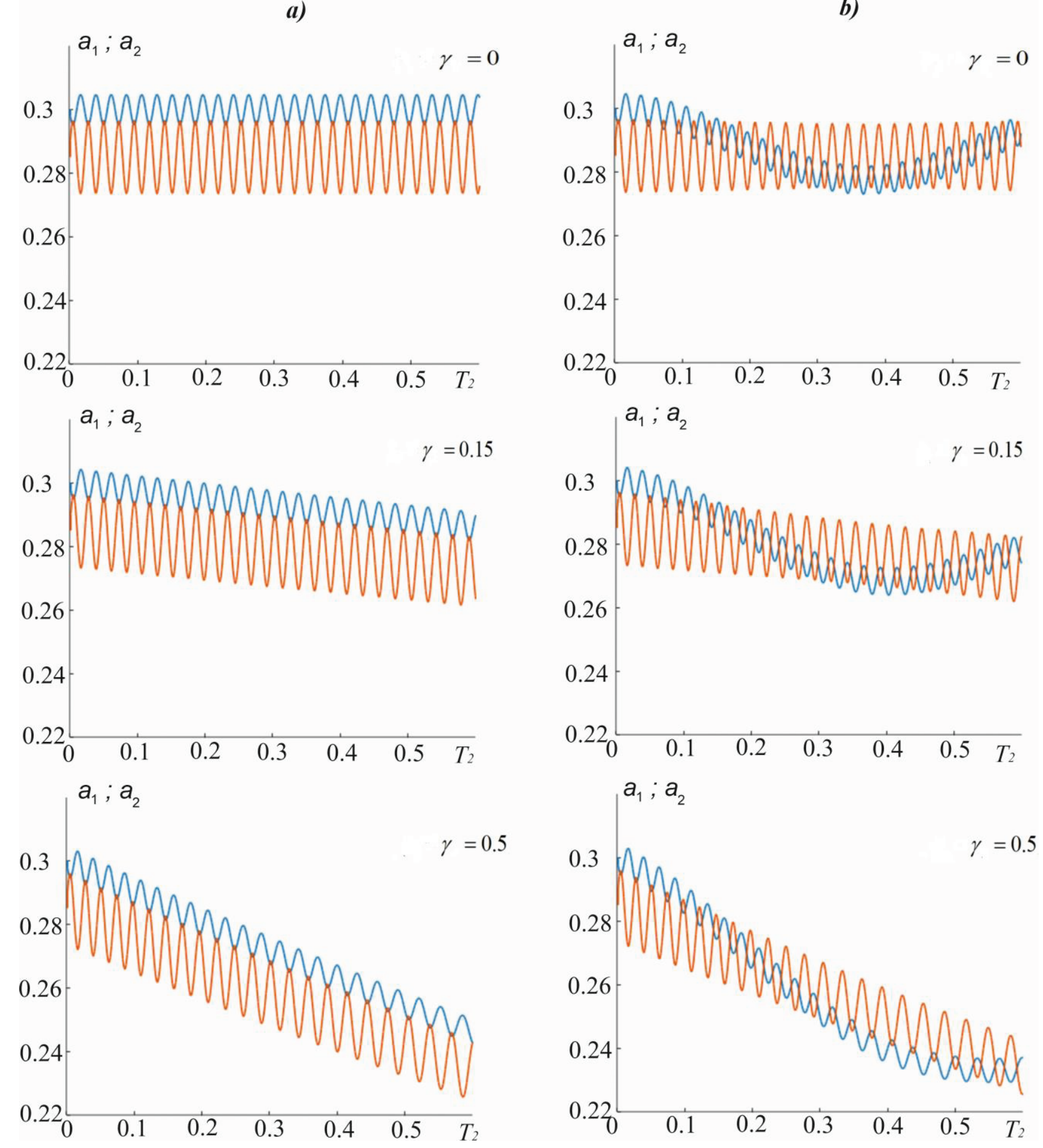

Figure 2. Dimensionless amplitude vs. dimensionless time:

(a) free vibrations, (b) forced vibrations at $f=1$ with the initial amplitude $a_{i 0}=0.3$,

blue line $-a_{1}$, orange line $-a_{2}$. 

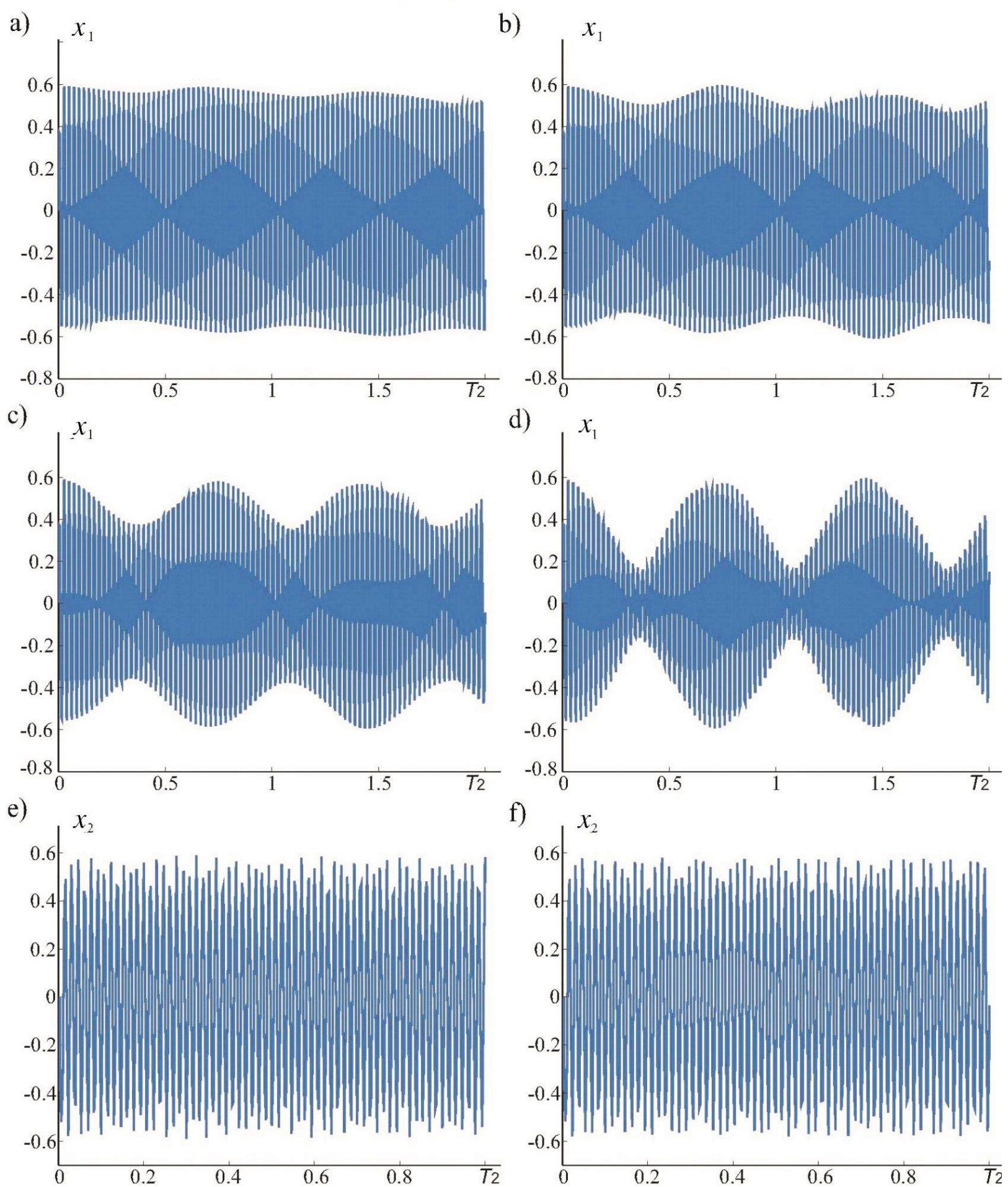

Figure 3. The time-dependence of the generalized displacements at different levels of external force magnitude for $\gamma=0$. 
Analysis of Nonlinear Forced Vibrations of Fractionally Damped Suspension Bridges Subject to One-to-One Internal Resonance
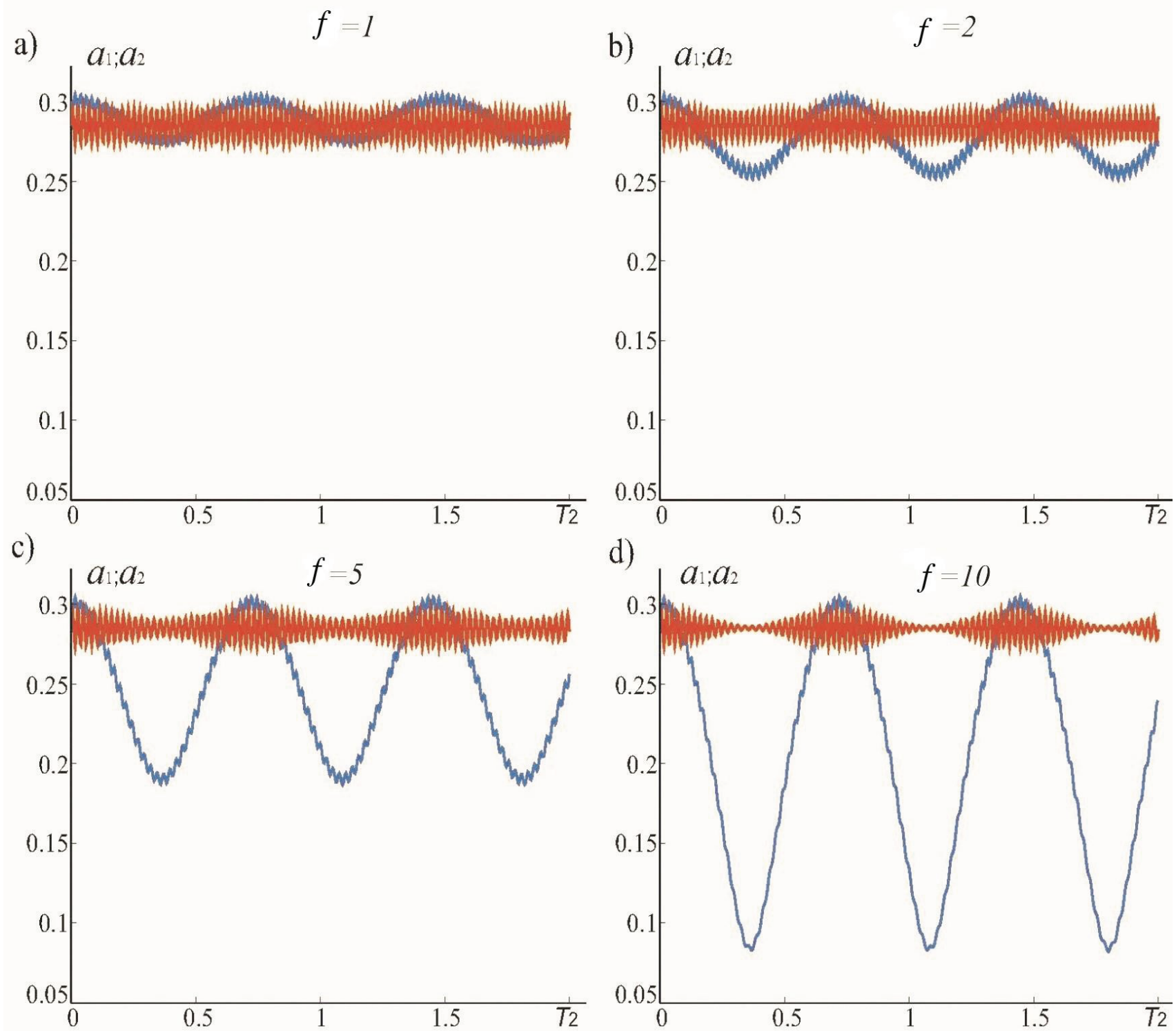

Figure 4. Time-dependence of the dimensionless amplitudes $a_{1}$ (blue) and $a_{2}$ (orange) at different levels of the external force amplitude.

\section{CONCLUSION}

Nonlinear force driven coupled vertical and torsional vibrations of a suspension bridge subject to the combination of external and internal resonances have been investigated for the case when its damping features are described by the fractional derivatives. From the above discussion the following conclusions could be reached.

If the external force is of order of $\varepsilon^{2}$ and the viscosity coefficients are of order of $\varepsilon$, then it is possible to obtain the approximate analytical solutions for the generalized displacements. As this takes place, the solution for the vertical displacement $x_{1}$ involves two parts: the first corresponds to the damping vibrations with damping coefficients and nonlinear frequencies dependent on the fractional parameters and describes the transient process, while the second one is nondamping in character and describes the steady-state regime, i.e., forced vibrations with the frequency of the exciting force and with the phase difference depending on the fractional 
parameter. The solution for the torsional displacement $x_{2}$ consists only from one term describing the transient process.

Moreover, in the transient processes, the damping coefficients and the frequencies of nonlinear vibrations depend on the square of the exciting force amplitude.

If the external force is of order of $\varepsilon^{3}$ and the viscosity coefficients are of order of $\varepsilon^{2}$, then the approximate analytical expressions for the generalized displacements $x_{1}$ and $x_{2}$ have been obtained by the method of successive approximations. The numerical analysis has shown that dimensionless amplitudes decrease with the increase in the fractional parameter $\gamma$, and the vertical amplitude and hence vertical displacement are much more susceptible to the higher vertical external force than torsional amplitude.

\section{FUNDING}

This research was carried out within the framework of the Government task, Project No 7.4.4 in the 2020 Fundamental Research Plan of RAASN and Ministry of Construction and Municipal Services of the Russian Federation.

\section{REFERENCES}

1. Abdel-Ghaffar A.M. Suspension bridge vibration: Continuum formulation. // Journal of Engineering Mechanics Division, 1982, Volume 108, pp. 1215-1232.

2. Abdel-Ghaffar A.M., Rubin L.I. Nonlinear free vibrations of suspension bridges: Theory and application. // ASCE Journal of Engineering Mechanics, 1983, Volume 109, Issue 1, pp. 313-345.

3. Rossikhin Yu.A., Shitikova M.V. Nonlinear free spatial vibrations of combined suspension systems. // Journal of Applied Mathematics and Mechanics, 1990, Volume 54, Issue 6, pp. 823-832.
4. Rossikhin Yu.A., Shitikova M.V. Analysis of nonlinear free vibrations of suspension bridges. // Journal of Sound and Vibration, 1995, Volume 186, Issue 3, pp. 369-393.

5. Rossikhin Yu.A., Shitikova M.V. Effect of viscosity on the vibrational processes in a combined suspension system. // Mechanics of Solids, 1995, Volume 30, Issue 1, pp. 157166.

6. Cevik M., Pakdemirli M. Nonlinear vibrations of suspension bridges with external excitation // International Journal of Nonlinear Mechanics, 2005, Vol. 40, pp. 901-923.

7. Nayfeh A.H. Perturbations Methods. New York: John Wiley \& Sons, 1973.

8. Shitikova M.V., Rossikhin Yu.A. Dynamics of suspension bridges: Nonlinear free and forced vibrations with internal resonances. // Plenary Lecture at the 5th European Conference of Civil Engineering (ECCIE '14), Florence, Italy Nov 22-24, 2014. In: Recent Advances in Civil Engineering and Mechanics (M.V. Shitikova, L. Vladareanu, C. Guarnaccia, Editors) WSEAS Press 2014, pp. 10.

9. Arioli G., Gazzola F. A new mathematical explanation of what triggered the catastrophic torsional mode of the Tacoma Narrows Bridge. // Applied Mathematical Modelling, 2015, Volume 39, pp. 901-912.

10. Lepidi M., Gattulli V. Non-linear interactions in the flexible multi-body dynamics of cable-supported bridge crosssections. // International Journal of NonLinear Mechanics, 2016, Volume 80, pp. 1428.

11. Capsoni A., Ardito R., Guerrieri A. Stability of dynamic response of suspension bridges. // Journal of Sound and Vibration, 2017, Volume 393, pp. 285-307.

12. Murphy P. Retrofit of suspension bridges in the central and eastern United State using distributed supplememtal damping. $\mathrm{PhD}$ Thesis, Michigan, 2000, 183 pages.

13. Strauss J.B. The Golden Gate Bridge. Report to the board of directors of the 
Analysis of Nonlinear Forced Vibrations of Fractionally Damped Suspension Bridges Subject to One-to-One Internal Resonance

Golden Gate Bridge and highway district, 1937.

14. Vincent G.S. Correlation of predicted and observed suspension bridge behavior. // Transactions of ASCE, 1962, Volume 127, pp. 646-666.

15. Vincent G.S. Golden Gate Bridge vibration studies. // Journal of Structural Division ASCE, 1958, Volume 84(ST6), 1817.

16. Vincent G.S. Golden Gate Bridge vibration studies. // Transactions of ASCE, 1962, Vol. 127, Part II, pp. 667-701.

17. Baron F., Arikan M., Hamati E. The effects of seismic disturbances on the Golden Gate Bridge. Report No. EERC 7631 Earthquake Engineering Research Center College of Engineering University of California, 1976.

18. Paine C.D. Supplement to the Final Report of the Chief Engineer - Golden Gate Bridge, Highway and Transportation District, 1970.

19. Tanaka H., Davenport A. Wind induced response of Golden Gate Bridge. // Proceedings of the Journal of Engineering Mechanics ASCE, 1983, Volume 109, Issue 1, pp. 296-312.

20. Abdel-Ghaffar A.M., Scanlan R.H. Ambient vibration studies of Golden Gate Bridge. I: Suspended structure. // ASCE Journal of Engineering Mechanics, 1985, Volume 111, Issue 4, pp. 463-482.

21. Abdel-Ghaffar A.M., Housner G.W. Ambient vibration tests of suspension bridge. // ASCE Journal of Engineering Mechanics, 1978, Volume 104, Issue 5, pp. 983-999.

22. Rossikhin Yu.A., Shitikova M.V. Application of fractional calculus for analysis of nonlinear damped vibrations of suspension bridges. // ASCE Journal of Engineering Mechanics, 1998, Volume 124, Issue 9, pp. 1029-1036.

23. Shitikova M.V. The fractional derivative expansion method in nonlinear dynamic analysis of structures. // Nonlinear Dynamics, 2020, Volume 99, Issue 1, pp. 109-122.
24. Shitikova M.V. The fractional derivative expansion method in nonlinear dynamics of structures: A memorial essay. // Transmutation Operators and Applications (V.V. Kravchenko and S.M. Sitnik, Editors) Trends in Mathematics, 2020, Chapter 29, pp. 653-670, Springer.

25. Rossikhin Yu.A., Shitikova M.V. Vliyanie vyazkosti na svobodnue prostranstvennue kolebaniya visyachei kombinirovannoi sistemu [Influence of viscosity of free spatial vibrations of a suspension combined system]. // News of Higher Educational Institutions. Construction, 1993, No. 4, pp. 26-29 (in Russian).

26. Samko S.G., Kilbas A.A., Marichev O.I. Fractional Integrals and Derivatives. Theory and Applications. Minsk: Nauka i Tekhnika, 1988 (in Russian).

27. Rossikhin Yu.A., Shitikova M.V. New approach for the analysis of damped vibrations of fractional oscillators. // Shock and Vibration, 2009, Volume 16, pp. 365387.

28. Rossikhin Yu.A., Shitikova M.V. Forced vibrations of a nonlinear oscillator with weak fractional damping. // Mechanics of Materials and Structures, 2009, Volume 4, Issue 9, pp. 1619- 1636.

29. Rossikhin Yu.A., Shitikova M.V. On fallacies in the decision between the Caputo and Riemann-Liouville fractional derivatives for the analysis of the dynamic response of a nonlinear viscoelastic oscillator. // Mechanics Research Communications, 2012, Volume 45, pp. 2227.

\section{СПИСОК ЛИТЕРАТУРЫ}

1. Abdel-Ghaffar A.M. Suspension bridge vibration: Continuum formulation. // Journal of Engineering Mechanics Division, 1982, Volume 108, pp. 1215-1232.

2. Abdel-Ghaffar A.M., Rubin L.I. Nonlinear free vibrations of suspension bridges: Theory and application. // ASCE 
Journal of Engineering Mechanics, 1983, Volume 109, Issue 1, pp. 313-345.

3. Rossikhin Yu.A., Shitikova M.V. Nonlinear free spatial vibrations of combined suspension systems. // Journal of Applied Mathematics and Mechanics, 1990, Volume 54, Issue 6, pp. 823-832.

4. Rossikhin Yu.A., Shitikova M.V. Analysis of nonlinear free vibrations of suspension bridges. // Journal of Sound and Vibration, 1995, Volume 186, Issue 3, pp. 369-393.

5. Rossikhin Yu.A., Shitikova M.V. Effect of viscosity on the vibrational processes in a combined suspension system. // Mechanics of Solids, 1995, Volume 30, Issue 1, pp. 157166.

6. Cevik M., Pakdemirli M. Nonlinear vibrations of suspension bridges with external excitation // International Journal of Nonlinear Mechanics, 2005, Vol. 40, pp. 901-923.

7. Nayfeh A.H. Perturbations Methods. New York: John Wiley \& Sons, 1973.

8. Shitikova M.V., Rossikhin Yu.A. Dynamics of suspension bridges: Nonlinear free and forced vibrations with internal resonances. // Plenary Lecture at the 5th European Conference of Civil Engineering (ECCIE '14), Florence, Italy Nov 22-24, 2014. In: Recent Advances in Civil Engineering and Mechanics (M.V. Shitikova, L. Vladareanu, C. Guarnaccia, Editors) WSEAS Press 2014, pp. 10.

9. Arioli G., Gazzola F. A new mathematical explanation of what triggered the catastrophic torsional mode of the Tacoma Narrows Bridge. // Applied Mathematical Modelling, 2015, Volume 39, pp. 901-912.

10. Lepidi M., Gattulli V. Non-linear interactions in the flexible multi-body dynamics of cable-supported bridge crosssections. // International Journal of NonLinear Mechanics, 2016, Volume 80, pp. 1428.

11. Capsoni A., Ardito R., Guerrieri A. Stability of dynamic response of suspension bridges. // Journal of Sound and Vibration, 2017, Volume 393, pp. 285-307.

12. Murphy P. Retrofit of suspension bridges in the central and eastern United State using distributed supplememtal damping. $\mathrm{PhD}$ Thesis, Michigan, 2000, 183 pages.

13. Strauss J.B. The Golden Gate Bridge. Report to the board of directors of the Golden Gate Bridge and highway district, 1937.

14. Vincent G.S. Correlation of predicted and observed suspension bridge behavior. // Transactions of ASCE, 1962, Volume 127, pp. 646-666.

15. Vincent G.S. Golden Gate Bridge vibration studies. // Journal of Structural Division ASCE, 1958, Volume 84(ST6), 1817.

16. Vincent G.S. Golden Gate Bridge vibration studies. // Transactions of ASCE, 1962, Vol. 127, Part II, pp. 667-701.

17. Baron F., Arikan M., Hamati E. The effects of seismic disturbances on the Golden Gate Bridge. Report No. EERC 7631 Earthquake Engineering Research Center College of Engineering University of California, 1976.

18. Paine C.D. Supplement to the Final Report of the Chief Engineer - Golden Gate Bridge, Highway and Transportation District, 1970.

19. Tanaka H., Davenport A. Wind induced response of Golden Gate Bridge. // Proceedings of the Journal of Engineering Mechanics ASCE, 1983, Volume 109, Issue 1, pp. 296-312.

20. Abdel-Ghaffar A.M., Scanlan R.H. Ambient vibration studies of Golden Gate Bridge. I: Suspended structure. // ASCE Journal of Engineering Mechanics, 1985, Volume 111, Issue 4, pp. 463-482.

21. Abdel-Ghaffar A.M., Housner G.W. Ambient vibration tests of suspension bridge. // ASCE Journal of Engineering Mechanics, 1978, Volume 104, Issue 5, pp. 983-999.

22. Rossikhin Yu.A., Shitikova M.V. Application of fractional calculus for analysis of nonlinear damped vibrations of 
Analysis of Nonlinear Forced Vibrations of Fractionally Damped Suspension Bridges Subject to One-to-One Internal Resonance

suspension bridges. // ASCE Journal of Engineering Mechanics, 1998, Volume 124, Issue 9, pp. 1029-1036.

23. Shitikova M.V. The fractional derivative expansion method in nonlinear dynamic analysis of structures. // Nonlinear Dynamics, 2020, Volume 99, Issue 1, pp. 109-122.

24. Shitikova M.V. The fractional derivative expansion method in nonlinear dynamics of structures: A memorial essay. // Transmutation Operators and Applications (V.V. Kravchenko and S.M. Sitnik, Editors) Trends in Mathematics, 2020, Chapter 29, pp. 653-670, Springer.

25. Россихин Ю.А., Шитикова М.В. Влияние вязкости на свободные пространственные колебания висячей комбинированной системы. // Известия вузов. Строительство, 1993, № 4, с. 26-29.

26. Самко С.Г., Килбас А.А., Маричев О.И. Интегралы и производные дробного порядка и некоторые их приложения. Минск: Наука и техника, 1987. - 688 с.

27. Rossikhin Yu.A., Shitikova M.V. New approach for the analysis of damped vibrations of fractional oscillators. // Shock and Vibration, 2009, Volume 16, pp. 365387.

28. Rossikhin Yu.A., Shitikova M.V. Forced vibrations of a nonlinear oscillator with weak fractional damping. // Mechanics of Materials and Structures, 2009, Volume 4, Issue 9, pp. 1619- 1636.

29. Rossikhin Yu.A., Shitikova M.V. On fallacies in the decision between the Caputo and Riemann-Liouville fractional derivatives for the analysis of the dynamic response of a nonlinear viscoelastic oscillator. // Mechanics Research Communications, 2012, Volume 45, pp. 2227.

Marina V. Shitikova, Advisor of the Russian Academy of Architecture and Construction Sciences (RAACS), Professor, Dr.Sc.; Research Center on Dynamics of Solids and Structures, Voronezh State Technical University; 84, 20-letija Oktyabrya, Voronezh, 394006, Russia; Senior Researcher, RAASN Research Institute of Structural Physics, Moscow, Russia; phone +7 (473) 271-52-68; fax +7 (473) 271-52-68; e-mail: mvs@vgasu.vrn.ru.

Aleks L. Katembo, PhD Student, Research Center on Dynamics of Solids and Structures; Voronezh State Technical University; 84, 20-letija Oktyabrya, Voronezh, 394006, Russia; e-mail: katembo2020@gmail.com.

Шитикова Марина Вячеславовна, советник Российской академии архитектуры и строительных наук (РАACH), профессор, доктор физикоматематических наук; руководитель международного научного Центра по фундаментальным исследованиям в области естественных и строительных наук; Воронежский государственный технический университет; 394006, Россия, г. Воронеж, ул. 20 лет Октября, д. 84; Главный научный сотрудник, Научноисследовательский институт строительной физики РАACH, Москва, Россия; тел. +7 (473) 271-52-68; факс +7 (473) 271-52-68; e-mail: mvs@vgasu.vrn.ru.

Катембо Алекс Лунгили, аспирант, Воронежский государственный технический университет; 394006, Россия, г. Воронеж, ул. 20 лет Октября, д. 84; E-mail: katembo2020@gmail.com. 